\title{
Survivin overexpression correlates with an apoptosis-resistant phenotype in chronic myeloid leukemia cells
}

\author{
GABRIELA NESTAL DE MORAES ${ }^{1,2}$, KARINA LANI SILVA ${ }^{1}$, \\ FLAVIA DA CUNHA VASCONCELOS ${ }^{1,2}$ and RAQUEL CIUVALSCHI MAIA ${ }^{1,3}$ \\ ${ }^{1}$ Laboratório de Hemato-Oncologia Celular e Molecular, Programa de Pesquisa em Hemato-Oncologia Molecular; \\ ${ }^{2}$ Programa de Pós-Graduação em Oncologia, Instituto Nacional de Câncer (INCA); \\ ${ }^{3}$ Serviço de Hematologia, INCA, Rio de Janeiro (RJ), Brazil
}

Received December 23, 2010; Accepted February 10, 2011

DOI: 10.3892/or.2011.1224

\begin{abstract}
Survivin is a member of the inhibitor of apoptosis protein family (IAP) that acts in both inhibition of apoptosis and regulation of the cell cycle. Despite the fact that survivin is overexpressed in almost all human malignancies, its expression is undetectable in most normal adult tissues, which is what makes it a potential target for anticancer interventions. The aim of this work was to investigate whether survivin is involved in resistance to idarubicin (ida), a drug commonly used in leukemia treatment. Cytotoxic assays using MTT showed that $1 \mu \mathrm{M}$ of ida could inhibit $50 \%$ of cell viability in K562, a chronic myeloid leukemia cell line. Western blotting analysis revealed that survivin expression was increased in the cell line after treatment with ida 0.5 and $1 \mu \mathrm{M}$ concentrations, protecting cells from ida-induced apoptosis. However, the highest ida concentrations tested were able to inhibit survivin levels and induce apoptosis in K562 cells, as evaluated by morphology and caspase- 3 and -9 activation. These results indicate that survivin expression is involved in ida resistance in K562 leukemic cells. Flow cytometry analysis of the cell cycle showed that ida induced G2/M arrest in these cells and there was a statistically significant positive correlation between survivin expression and the percentage of cells in $\mathrm{G} 2 / \mathrm{M}$ phase. This work supports the idea that survivin may contribute to an apoptosis-resistant phenotype by inhibiting ida-induced apoptosis and preventing cells from progressing in the cell cycle.
\end{abstract}

\section{Introduction}

Resistance to chemotherapeutic agents remains a major obstacle for the effective treatment of many cancers. Several mechanisms

Correspondence to: Dr Raquel C. Maia, Laboratório de HematoOncologia Celular e Molecular, Programa de Pesquisa em Hemato-Oncologia Molecular, Instituto Nacional do Câncer, Rio de Janeiro, RJ, Brazil

E-mail:rcmaia@inca.gov.br

Key words: survivin, apoptosis, idarubicin, chemoresistance, leukemia are thought to be involved in the development of multidrug resistance (MDR) and resistance to apoptosis has emerged as an important one (1). Taken into account that chemoresistance may arise from failure of neoplastic cells to successfully undergo apoptosis, many pathways such as the inhibitor of apoptosis proteins (IAPs) overexpression have been investigated in order to clear if these proteins might be involved in this homeostatic imbalance $(2,3)$. Survivin is a member of IAPs that is expressed in embryonic and fetal organs, but not in the majority of terminally differentiated normal adult tissues (4). On the other hand, it is strongly expressed in most of human tumor types, what makes this protein a potential target for anticancer interventions (5). Survivin overexpression is frequently associated with an unfavorable prognosis and resistance to chemotherapy and radiotherapy (6). Survivin not only regulates apoptosis, but also controls cell division (7). Its expression is increased in the G2/M phase of the cell cycle (8), a process that requires a cell-cycle dependent transcription of the survivin gene during the mitotic phase, as well as post-translational modifications of the protein (9). Such pathway occurs dominantly in normal cells, but the upregulation of survivin in $\mathrm{G} 2 / \mathrm{M}$ phase has already been observed in tumor cell lines (10).

In chronic myeloid leukemia (CML), survivin was found to be expressed in accelerated and blastic phases but it was low or undetectable in chronic phase of CML (11-13), what suggests that survivin may be involved in the evolution from the chronic to the blastic phase of CML. Despite the recent incorporation of imatinib in the treatment of the blast phase CML (14), the schema of treatment of blast phase CML has been very similar to that used in acute myeloid leukemia as the association of one anthracycline, daunorubicin or idarubicin (ida), with cytosine arabinoside (ara-c) (15). It has been already noted that ida (a semisynthetic derivative of daunorubicin) is more active than daunorubicin in acute myeloid leukemia and it has also showed to be a good promise to blast phase CML (15-17). More recently it was suggested that the association between imatinib and ida would be a good schema for blast phase CML patients (18). The origin of ida action is from the ability to diffuse across the cell membrane, intercalate between DNA base pairs and target topoisomerase II, leading to DNA single- and double-strand breaks (19). Compared to other anthracyclines, this drug has the highest 
lipophilicity, characteristic that leads to the fastest accumulation in the nucleus and the greatest cytotoxicity (20).

Considering that survivin is involved in chemoresistance in cancer, the present study aimed to investigate the relationship between survivin expression and resistance to ida in a CML cell line. We found that CML cells exposed to ida had survivin expression increased, consistent with an apoptosisresistant phenotype. In addition, ida induced G2/M arrest and a correlation could be established between the percentage of cells arrested in this phase and survivin levels. These findings suggest that survivin overexpression is not only involved in ida resistance in CML cells, but also related to the positive regulation this protein undergoes during preparation to enter G2/M phase and play its relevant role on chromossome segregation and cell division.

\section{Materials and methods}

Drugs and chemicals. Ida (Idarubicin-Zavedos ${ }^{\circledR}$ ) and doxorubicin (doxorubicin hydrochloride ${ }^{\circledR}$ ) were provided by Pharmacia-Upjohn (Milan, Italy) and Eurofarma (São Paulo, Brazil), respectively. The drugs were diluted in distilled water and serial dilutions in RPMI-1640 were performed prior to use. Tris (tris hidroximethyl aminomethane) was purchased from Merck and MTT (3-(4,5-dimethylthiazlol-2-yl)-2,5diphenyltetrazolium bromide), from USB. Ficoll-Hypaque, PBS (phosphate-buffered saline), RNAse (ribonuclease A) and DMSO (dimethyl sulfoxide) were obtained from Sigma Aldrich (St. Louis, MO, USA).

Cell culture. The human blast crisis CML K562 cell line was obtained from the American Type Culture Collection, ATCC, Manassas, VA, USA. Cells were cultured in RPMI-1640 medium (LGC Biotechnology) supplemented with $10 \%$ heatinactivated fetal bovine serum $\left(\mathrm{Gibco}^{\circledR}\right)$ and maintained at $37^{\circ} \mathrm{C}$ under $5 \% \mathrm{CO}_{2}$ in a humidified atmosphere.

Cytotoxicity assay. Cell viability was evaluated by a modified MTT assay (21). K562 cells $\left(10^{5} \mathrm{ml}^{-1}\right)$ were treated with ida for 24,48 and $72 \mathrm{~h}$, at a final concentration ranging from $1 \mathrm{nM}$ to $10 \mu \mathrm{M}$. Briefly, cells were plated onto 96-well plates in $200 \mu \mathrm{l}$ growth medium and $20 \mu \mathrm{l}$ of MTT $(5 \mathrm{mg} / \mathrm{ml}$ in phosphate-buffered saline) reagent was added to each well. After incubation with MTT for $4 \mathrm{~h}$ at $37^{\circ} \mathrm{C}$, the supernatant was removed and $150 \mu \mathrm{l}$ of DMSO were added to dissolve the formazan salt. Absorbance at $492 \mathrm{nM}$ was measured with an ELISA reader (DTX 800 Multimode Detector from Beckman Coulter, Fullerton, CA, USA) and the percentage of cell viability was assessed as: (absorbance of ida treated cells/absorbance of untreated cells) $x$ 100. The concentrations and experiments were done in triplicate. This assay was done as a preliminary experiment to determine de $\mathrm{IC}_{50}$ (concentration able to inhibit viability of cells in 50\%).

Western blotting. For survivin detection, pellets of $2 \times 10^{6}$ cells were washed three times with PBS and lysed in ressuspension buffer (40 $\mathrm{mM}$ Tris- $\mathrm{HCl} ; 40 \mathrm{mM}$ EDTA; $\mathrm{pH} 7.5$ ) and SDS (dodecyl sodium sulfate) $10 \%$ for $15 \mathrm{~min}$ at $100^{\circ} \mathrm{C}$. The total protein was determined using Bio-Rad protein assay solution and $70 \mu \mathrm{g}$ of lysates were subjected to
SDS-PAGE onto $15 \%$ polyacrylamide gels (acrylamide/bisacrylamide $30 \% ; 25 \% \mathrm{H}_{2} \mathrm{O} ; 115 \mathrm{mM}$ Tris- $\mathrm{HCl}$ buffer $\mathrm{pH} 8.8$; Temed; APS). After electrophoresis, proteins were transferred to Hybond-P membranes, which were subsequently stained with Ponceau red to assure equal protein loading and transfer. The blots were blocked for $1 \mathrm{~h}$ at room temperature with $5 \%$ non-fat dry milk TBS containing $0.2 \%$ Tween-20 before incubation with antibodies against Survivin (1:1000 dilution, R\&D Systems, Minneapolis, MN, USA) or $\beta$-actin (1:1000 dilution, Sigma-Aldrich) for $1 \mathrm{~h}$ in the same solution. Secondary antibodies comprised horseradish peroxidase (HRP)-labelled anti-mouse antibody (1:1000 dilution; GE Healthcare, Buckinghamshire, UK) or anti-rabbit antibody (1:1000 dilution; GE Healthcare). Blots were exposed to them for $1 \mathrm{~h}$, before four washing steps of $10 \mathrm{~min}$ each with TBS-Tween. Antibody complexes were visualized by the ECL detection system (GE Healthcare) and band intensities were quantified using the VisionWorks software. The expression of survivin was normalized with respect to $\beta$-actin. As a negative control for survivin expression, lymphocytes were collected from normal individuals and isolated on a FicollHypaque gradient.

Detection of apoptosis. Activation of caspases is a well known key event in the apoptotic process and has been used as a biochemical marker for induction of apoptosis in leukemic cells (22). Thus, cleavage of procaspases-3 and -9 were analyzed by Western blotting. The method performed has undergone some differences compared to the previously described. A total of $80 \mu \mathrm{g}$ of lysates was loaded and primary antibodies against caspase-3 (1:500 dilution, BD Biosciences, San Jose, CA, USA), caspase-9 (1:500 dilution, R\&D Systems) and $\beta$-actin (1:1000 dilution, Sigma-Aldrich) were incubated overnight in TBS-milk. Membranes were probed with the secondary antibody horseradish peroxidase (HRP)-labelled anti-mouse antibody (1:1000 dilution; GE Healthcare).

For morphological analysis of apoptosis, aproximately $2 \times 10^{4}$ cells were harvested at different times after ida treatment. Then, K562 cells were centrifugated onto slides by cytospin (350 rpm, $5 \mathrm{~min}$ ) and stained with May-Grunwald Giemsa. Apoptotic cells were scored by their condensed chromatin and fragmented nuclei compared to non-apoptotic cells and microscopically identified in a x40 magnification. The percentage of apoptotic cells was determined by counting at least 200 cells from three separate preparations and calculated from the ratio: (number of apoptotic cells/total number of cells) x 100. Results were visualized and registered in an Eclipse E200 Nikon microscope connected to a Digital Sight system. Images were captured by the NIS-Elements F2.30 software.

Cell cycle analysis. After ida treatment, $10^{6}$ cells were harvested, washed in PBS and incubated with $500 \mu \mathrm{l}$ of propidium iodide (PI) staining solution (PI $50 \mu \mathrm{g} / \mathrm{ml}$ diluted in citrate buffer $4 \mathrm{mM}$ and Triton X-100 0.3\%) and RNAse (100 $\mu \mathrm{g} / \mathrm{ml}$ diluted in citrate buffer $40 \mathrm{mM}$ ) for $15 \mathrm{~min}$ at room temperature. DNA content was determined on a flow cytometer (FACScan Becton-Dickinson, San Jose, CA, USA). A total of 10,000 events were acquired per sample and populations in cell cycle phases were quantified using the WinMDI software. 
Statistical analysis. Statistical analysis of the results was performed using the Graph Pad Prism 4.0 software. Data analysis was done using the Student's t-test to compare differences in viability between cells exposed or not to ida. The Pearson's test was applied to investigate a correlation between survivin protein expression and the percentage of cells arrested in $\mathrm{G} 2 / \mathrm{M}$ phase of the cell cycle. $\mathrm{p}<0.01$ was considered statistically significant.

\section{Results}

Ida cytotoxicity in K562 cells. Because previous studies have shown that ida exerts cytotoxic effects on leukemic cells $(23,24)$, we conducted preliminary experiments to determine the $\mathrm{IC}_{50}$ dose of ida in K562 cells. The MTT assay revealed that ida is cytotoxic at concentrations above $1 \mu \mathrm{M}$, since the concentrations ranging from $1 \mathrm{nM}$ to $10 \mu \mathrm{M}$ did not display a statistically significant effect regarding inhibition in cell viability (Fig. 1). After $48 \mathrm{~h}$ of incubation, we found that ida $1 \mu \mathrm{M}$ was able to cause a $50 \%$ decrease in cell viability, which was progressively inhibited when K562 cells were treated with higher concentrations. On the basis of our observations, we further examined the effect of ida $\mathrm{IC}_{50}$, as well as half of $\mathrm{IC}_{50}$ value, in subsequent experiments. Higher concentrations of ida $(10,15$ and $20 \mu \mathrm{M})$ were also tested with the objective of understanding drug mechanisms.

Survivin modulation as a response to ida treatment. Survivin has been reported to modulate the balance between cell viability and cell death in cancer (25). Therefore, we examined the effects of ida on the expression of survivin in K562 cells. Western blotting of total cell extracts revealed that ida was able to induce survivin expression at lower concentrations (Fig. 2). After cell treatment with ida 0.5 and $1 \mu \mathrm{M}$ for $48 \mathrm{~h}$, there was an increase in survivin expression to 2.5-2.2-fold, respectively, which was quantified through the survivin/ $\beta$-actin densitometric ratio. However, the highest ida concentrations tested reduced survivin levels in a significant way. It was possible to observe a progressive reduction in the levels of survivin when ida concentration was progressively increased (Fig. 2). Survivin modulation was not a general effect of members of anthracyclines, since K562 cells exposure to doxorubicin did not lead to any changes in survivin expression (Fig. 3). These data show that ida modulated survivin expression, suggesting that this protein may be a specific target for ida in leukemic cells.

Morphological changes of ida-treated $K 562$ cells. As survivin expression is involved in tumour resistance to chemotherapeutic drugs in leukemia (26) and is associated with disease progression in CML (12), the next step of our work was to evaluate whether survivin expression would correlate with an apoptosis-resistant phenotype in these cells. Morphologically, cells undergoing apoptosis are characterized by the appearance of apoptotic bodies, nuclear fragmentation, cromatin condensation and cell retraction (27). Thus, the next step of our work was to analyze morphological features of apoptosis in K562 cells exposed to ida. By using morphological analysis, it was possible to observe that there was a dose-dependent induction of apoptosis after ida treatment. Despite cells treated

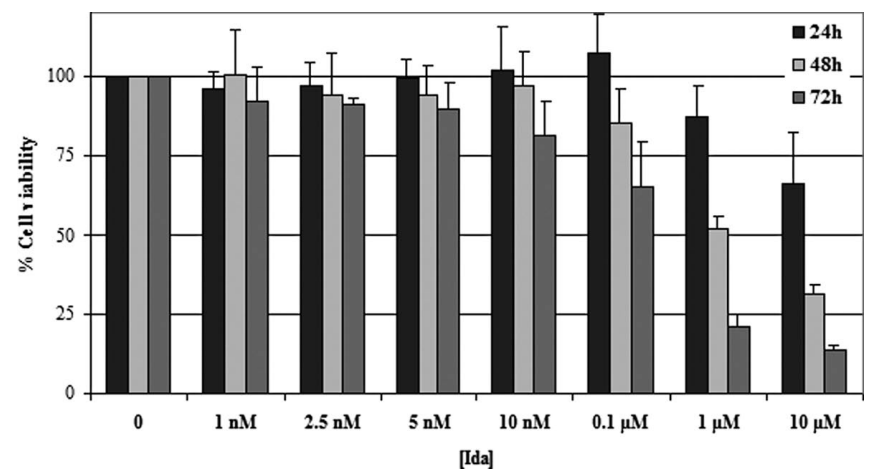

Figure 1. Determination of the concentration of idarubicin (ida) capable of inhibiting viability of $\mathrm{K} 562$ cells in $50 \%\left(\mathrm{IC}_{50}\right)$, using the MTT assay. Cells were treated or not with the indicated concentrations of ida for 24, 48 and $72 \mathrm{~h}$. The viability of untreated cells was set at $100 \%$. Ida decreased cell viability in a dose- and time-dependent manner. $\mathrm{IC}_{50}$ value found for $\mathrm{K} 562$ cells was $1 \mu \mathrm{M}$ for $48 \mathrm{~h}$. All data are the mean \pm standard deviation of three independent experiments. " $\mathrm{p}<0.01$; Student's t-test.

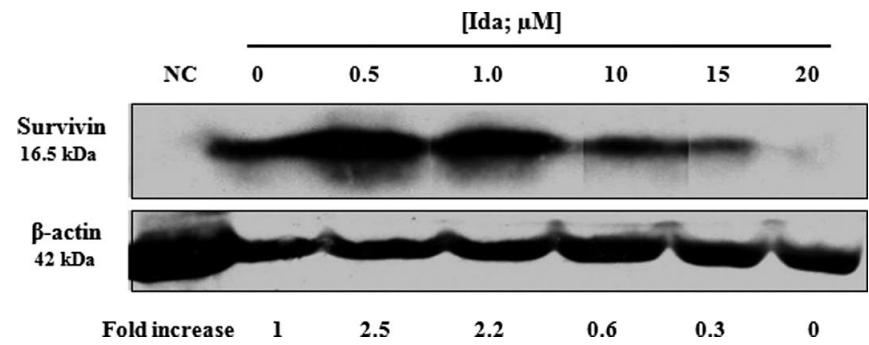

Figure 2. Western blotting analysis of the expression of survivin in K562 cells treated or not with idarubicin (ida) for $48 \mathrm{~h}$. Treatment with ida increases Survivin levels in $>200 \%$, compared to untreated cells. However, survivin expression is reduced with the increase in ida concentrations. Changes in survivin levels induced by ida were expressed through the survivin/actin densitometric ratio. The blots shown are representative of three independent experiments. NC, negative control (see Materials and methods).

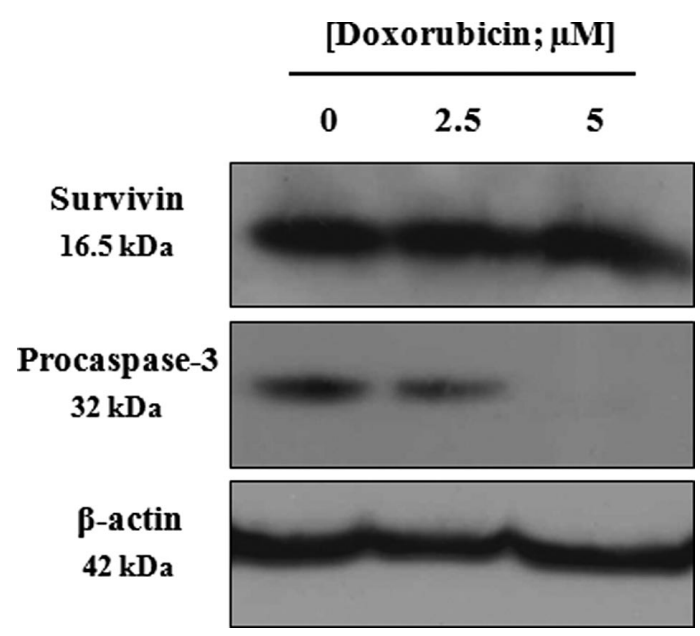

Figure 3. Western blotting analysis of the expression of survivin in K562 cells treated or not with doxorubicin for $48 \mathrm{~h}$. Doxorubicin exposure was able to induce apoptosis in K562 cells, as visualized by the disappearance of the precursor form of caspase-3. The apoptotic cascade activated by doxorubicin in these cells did not involve survivin modulation, since its levels remained unaltered after drug treatment. The blots shown are representative of three independent experiments. 

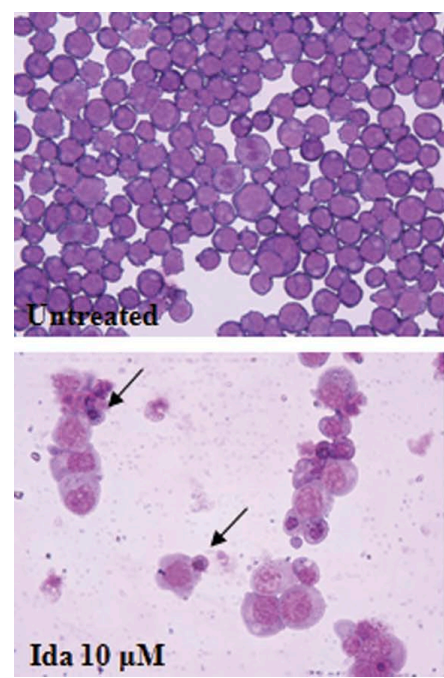
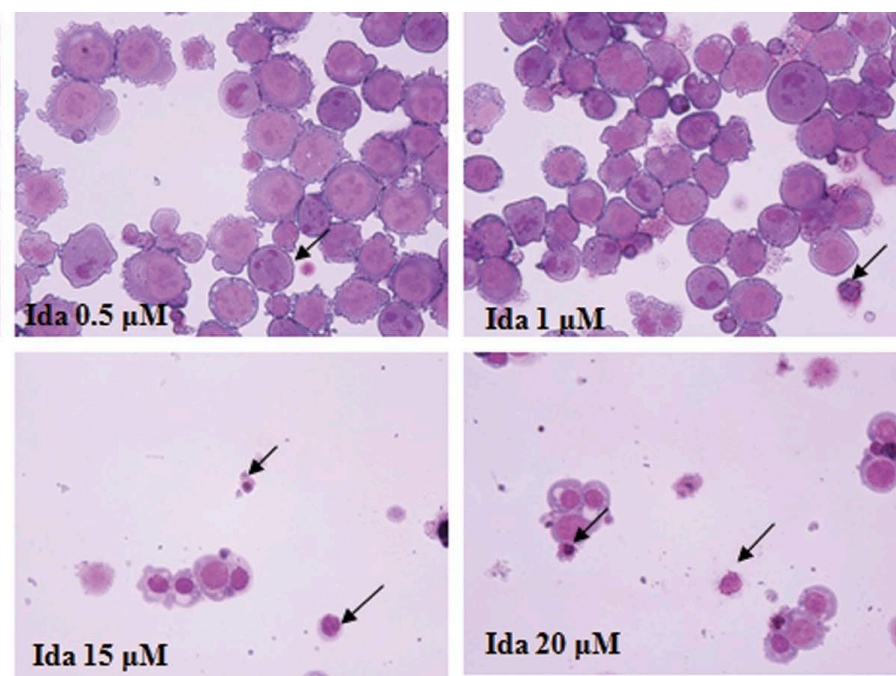

Figure 4. Representative images of May-Grunwald/Giemsa stained K562 cells, exposed or not to idarubicin (ida) for 48 h. Morphological analysis revealed that ida can induce apoptosis in K562 cells in a dose-dependent manner. The arrows point to the apoptotic features observed after ida treatment: presence of apoptotic bodies, chromatin condensation and nuclear fragmentation. Magnification x40.

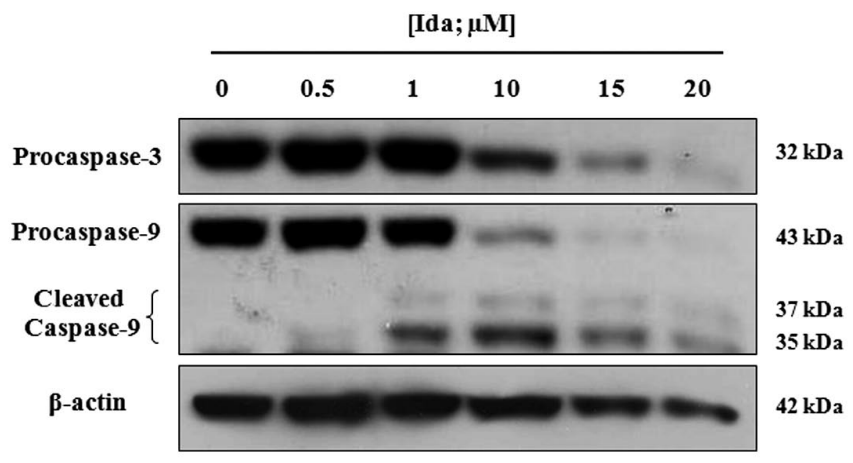

Figure 5. Western blotting analysis of caspase activation after idarubicin (ida) treatment. K562 cells were exposed to various ida concentrations for $48 \mathrm{~h}$. Ida 0.5 and $1 \mu \mathrm{M}$ did not alter procaspase-3 levels, while the highest concentrations tested were able to reduce its levels, progressively. Procaspase-9 cleavage could already be observed after treatment with ida $1 \mu \mathrm{M}\left(\mathrm{IC}_{50}\right)$ and occurs in a dose-dependent manner.

with ida at 0.5 and $1 \mu \mathrm{M}$ concentrations displayed some apoptotic features, as indicated by the arrows (Fig. 4), there were already many cells which remained unaltered. Compared with untreated cells, these concentrations were able to induce only 17 and $25 \%$ apoptosis in K562 cells, respectively. The highest concentrations tested $(10,15$ and $20 \mu \mathrm{M})$ caused a greater cytotoxicity against K562 cells with the reduction in number of live cells and the appearance of many apoptotic bodies in the fields observed (Fig. 4). These data suggest that ida induced apoptotic cell death in K562 CML cells.

Ida induces caspase-9 and caspase-3 activation in K562 cells. To confirm morphological data regarding induction of apoptosis in K562 cells by ida, we assessed caspase- 3 and -9 activation through Western blotting. The processing of caspase- 3 was judged by the disappearance of the $32-\mathrm{kDa}$ precursor (procaspase-3), since the caspase-3 antibody used for Western blot analysis did not detect the active 17-kDa subunit. Concomitantly with high survivin expression, exposure of
K562 cells to 0.5 and $1 \mu \mathrm{M}$ ida did not alter procaspase-3 levels (Fig. 5). On the other hand, ida downregulated procaspase-3 levels as concentrations were progressively increased, what was associated with inhibition of survivin expression. The activation of caspase- 9 was detected after exposure to $1 \mu \mathrm{M}$ ida for $48 \mathrm{~h}$ and was dose-dependent (Fig. 5), indicating that ida-induced cell death is mediated by the activation of caspases. These results suggest that survivin is involved in resistance to ida-induced apoptosis.

Ida induces $G 2 / M$ arrest. Survivin displays great relevance for cell cycle progression (28) and acts during G2/M phase transition (29). Consistent with this, the possible involvement of survivin in cell division was analyzed by flow cytometry. DNA content histograms revealed that ida at 0.5 and $1 \mu \mathrm{M}$ concentrations induced G2/M arrest in K562 cells (Fig. 6). There was an accumulation of 50 and $39 \%$ of cells, respectively, in G2/M phase, which was associated with induction of survivin expression by ida. The highest ida concentrations tested did not have the same effect upon cells, since there was not an arrest in cell cycle, neither high survivin levels. In addition, ida led to the appearance of a sub-G0/G1 peak in a dose-dependent manner, corroborating our morphological analysis regarding nuclear fragmentation. These data suggest that survivin overexpression may also occur as a response to the regulation survivin undergoes while playing its role in the cell cycle.

Correlation between survivin expression and G2/M arrest. Our results collectively allowed us to establish a correlation between survivin expression and the G2/M phase. When we compared changes that ida induced in survivin levels with the percentage of cells arrested in G2/M, we obtained a statistically significant positive correlation between these two variables (Pearson $r=0.9695 ; \mathrm{p}=0.0014$ ). Altogether, our results suggest that survivin may contribute to an apoptosis- 

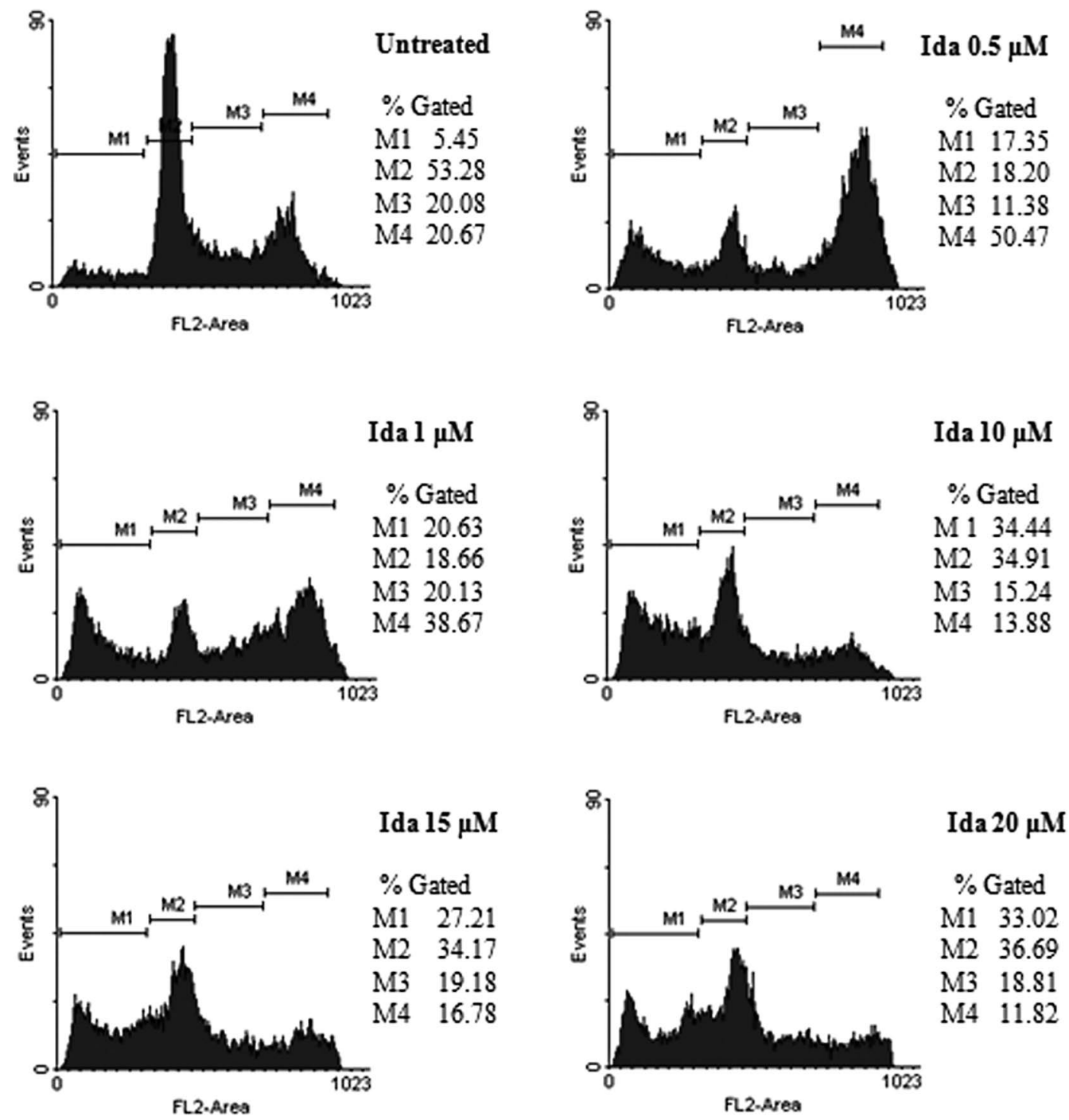

Figure 6. Flow cytometry analysis of idarubicin (ida)-induced alteration in K562 cells DNA content. Cell cycle was analyzed using PI-stained K562 cells, after $48 \mathrm{~h}$ of incubation with the drug. The cell cycle phases were sub-G0/G1 (M1), G0/G1 (M2), S (M3) and G2/M (M4). The percentage of cells in each phase was calculated from the histograms. Ida induced $\mathrm{G} 2 / \mathrm{M}$ arrest in 0.5 and $1 \mu \mathrm{M}$. The appearance of a sub-G0/G1 peak showed that all concentrations tested led to DNA fragmentation.

resistant phenotype by inhibiting ida-induced apoptosis and preventing cell cycle progression.

\section{Discussion}

Evasion from apoptosis is a critical event in tumorigenesis and constitutes a hallmark of cancer (30). Survivin is an inhibitor of apoptosis protein (IAP), whose overexpression is a very common feature observed in many types of malignancies and seems to underlie tumor development and resistance to therapy (31). Therefore, targeting survivin may have a direct role in circumventing drug resistance and sensitizing cancer cells to apoptosis induced by chemotherapeutic agents (32). In fact, it has been already shown that targeting survivin is a potential strategy, since survivin inhibition induced by anticancer agents, antisense oligonucleotides or RNA interference techniques has enhanced sensitivity of neoplastic cells to apoptosis (33-37). Hence, our study aimed to understand if survivin overexpression would be involved in resistance to ida and if it would be possible to modulate survivin expression through ida treatment in K562 cells. Our interest in studying ida is due to the fact that this drug is very effective in leukemia patients (38), besides it is more effective than other members of anthracyclines in inducing apoptosis (24).

First, our study demonstrated that ida at $1 \mu \mathrm{M}$ concentration was capable to induce a decrease of $50 \%\left(\mathrm{IC}_{50}\right)$ in cell viability after $48 \mathrm{~h}$ of incubation (Fig. 1). The inhibition in cell viability was not significantly observed when K562 cells were exposed to lower concentrations. Next, we aimed to analyze if ida treatment would be able to modulate survivin levels, because some forms of chemoresistance in leukemia may start from failure of tumour cells to undergo apoptosis and survivin could play a role in this defect. Interestingly, survivin was upregulated after a 48-hour incubation with ida 0.5 and $1 \mu \mathrm{M}$ in $\mathrm{K} 562$ cells, as demonstrated by Western blotting (Fig. 2). Other studies have demonstrated that some antineoplastic drugs can induce an increase in antiapoptotic protein levels. Survivin overexpression was observed when 


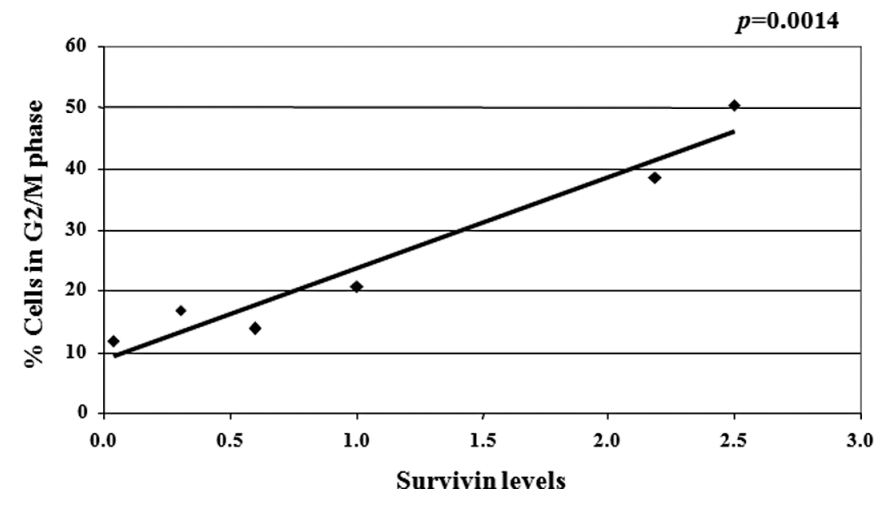

Figure 7. Correlation between survivin expression and the percentage of K562 cells in G2/M phase. Cells were incubated with idarubicin (ida) for $48 \mathrm{~h}$. Survivin levels are expressed by the densitometric ratio Survivin $/ \beta$-actin The Pearson r (0.9695) and p (0.0014) values observed reveals a significant positive correlation between the variables analyzed.

neuroblastoma cells were treated with staurosporine, leading them to an apoptosis-resistant phenotype (39). Another study has demonstrated that leukemic cells exposed to ida showed an upregulation in the Bcl-2 antiapoptotic protein levels (40), indicating that some concentrations of ida may activate leukemic cellular mechanisms of defense.

The next step was to investigate if survivin would confer resistance to ida and protect cells from apoptosis. After $48 \mathrm{~h}$ of incubation, ida at 0.5 and $1 \mu \mathrm{M}$ concentrations did not lead to procaspase-3 processing, indicating that the drug did not activate the effector caspase (Fig. 5). Confirming these data, cellular morphological analysis showed that, after treatment with 0.5 and $1 \mu \mathrm{M}$ of ida, there were still many cells which did not display apoptotic features and remained similar to the control of untreated cells (Fig. 4). In an interesting way, the exposure of $\mathrm{K} 562$ cells to the highest ida concentrations led to survivin downregulation (Fig. 2). In accordance with other studies afore-mentioned, which demonstrated that ida can efficiently induce apoptosis in leukemic cells $(22,24)$, cells expressing low survivin levels underwent apoptosis, as showed by caspase- 3 and -9 activation (Fig. 5) and by the observation of many apoptotic figures (Fig. 4). Consistent with this, two recent reports from our group show that treatment of K562 CML cells with imatinib (41) or a new antitumoral compound, a pterocarpanquinone structurally related to lapachol (42), resulted in survivin downregulation and cell death, showing that many chemotherapeutic agents can regulate survivin while inducing apoptosis. These data suggest that survivin expression is closely involved in resistance to ida treatment, since K562 cells displaying high survivin levels had a defect in the activation of the apoptotic machinery. This work is the first to investigate a possible association between survivin and resistance to ida in leukemic cells.

Contrasting with the effect observed after ida exposure, incubation of K562 cells with doxorubicin, another anthracycline, did not modulate survivin expression (Fig. 3). It is important to highlight that doxorubicin is also effective in inducing apoptosis in K562 cells, as visualized by the reduction in procaspase-3 levels (Fig. 3), demonstrating that not all anthracyclines have survivin as a target to activate the apoptotic cascade. These results show that doxorubicin might overcome resistance and affect sensitivity by activating other cell signaling pathways.

The results regarding ida-induced survivin overexpression prompted us to analyze the involvement of survivin in cell cycle since it is known that survivin has a dual role, having properties both antiapoptotic and proliferative (43). Thus, we verified that ida 0.5 and $1 \mu \mathrm{M}$ induced a $\mathrm{G} 2 / \mathrm{M}$ arrest after $48 \mathrm{~h}$ of treatment, reaching $50 \%$ of K562 cells in these phases of cell cycle (Fig. 6). Other groups also described that ida was able to induce G2/M arrest in both K562 (19) and HL60 cells (44), indicating that it may be a general ida mechanism of action. Reinforcing our hypothesis, we could establish a correlation between the percentage of cells in G2/M and survivin expression (Fig. 7). We found that there was a positive correlation between the variables, which was statistically significant $(\mathrm{p}=0.0014)$. Confirming our results, it was demonstrated that G2/M-arrested cultures showed an upregulation in survivin expression (39) and that survivin is required for checkpoint activation following taxol exposure (45). These data strongly suggest that survivin overexpression also occurs as a response to the cell cycle modulation induced by ida treatment, being related to the regulation survivin is submitted throughout progression into $\mathrm{G} 2$ and $\mathrm{M}$ phases.

In conclusion, our work demonstrates that survivin upregulation was assigned to the cell cycle status, being closely associated with its role in cell division. Moreover, an important point to emphasize is that survivin overexpression was associated with ida resistance in chronic myeloid leukemia cells, corroborating previous studies which described survivin role in chemoresistance in other models. This work provided some spectrum of biologic parameters that may have implications in the understanding of survivin dynamics and role in chemoresistance.

\section{Acknowledgements}

This study was supported by grants from INCT, FAPERJ, FINEP and Swissbridge Foundation.

\section{References}

1. Johnstone RW, Ruefli AA and Lowe SW: Apoptosis: a link between cancer genetics and chemotherapy. Cell 108: 153-164, 2002.

2. Hunter AM, LaCasse EC and Korneluk RG: The inhibitors of apoptosis (IAPs) as cancer targets. Apoptosis 12: 1543-1568, 2007.

3. Krepela E, Dankova P, Moravcikova E, et al: Increased expression of inhibitor of apoptosis proteins, survivin and XIAP, in non-small cell lung carcinoma. Int J Oncol 35: 1449-1462, 2009.

4. Ambrosini G, Adida C and Altieri DC: A novel anti-apoptosis gene, survivin, expressed in cancer and lymphoma. Nat Med 3: 917-921, 1997.

5. Zaffaroni N, Pennati M and Daidone MG: Survivin as a target for new anticancer interventions. J Cell Mol Med 9: 360-372, 2005.

6. Yamamoto H, Ngan CY and Monden M: Cancer cells survive with survivin. Cancer Sci 99: 1709-1714, 2008.

7. Li F, Ambrosini G, Chu EY, Plescia J, et al: Control of apoptosis and mitotic spindle checkpoint by survivin. Nature 396: 580-584, 1998.

8. Zangemeister-Wittke U and Simon HU: An IAP in action: the multiple roles of survivin in differentiation, immunity and malignancy. Cell Cycle 3: 1121-1123, 2004.

9. Altieri DC: The case for survivin as a regulator of microtubule dynamics and cell-death decisions. Curr Opin Cell Biol 18: 609-615, 2006 
10. Pennati M, Folini M and Zaffaroni N: Targeting survivin in cancer therapy: fulfilled promises and open questions. Carcinogenesis 28: 1133-1139, 2007

11. Mori A, Wada H, Nishimura Y, et al: Expression of the antiapoptosis gene survivin in human leukemia. Int $\mathbf{J}$ Hematol 75 161-165, 2002.

12. Badran A, Yoshida A and Wano S: Expression of the antiapoptotic gene survivin in chronic myeloid leukemia. Anticancer Res 23: 589-592, 2003.

13. Conte E, Stagno F, Guglielmo P, et al: Survivin expression in chronic myeloid leukemia. Cancer Lett 225: 105-110, 2005.

14. Silver RT: The blast phase of chronic myeloid leukaemia. Best Pract Res Clin Haematol 22: 387-394, 2009.

15. Tallman MS, Gilliland DG and Rowe JM: Drug therapy for acute myeloid leukemia. Blood 106: 1154-1163, 2005.

16. Lambertenghi-Deliliers G, Annaloro C, Cortellaro M, et al: Idarubicin in blastic crisis of chronic myelogenous leukemia Haematologica 76: 406-408, 1991.

17. Schneller F, Schuler M, Schumacher K, et al: Idarubicin and intermediate-dose cytarabine for myeloid blast crisis of chronic myelogenous leukemia-results of a phase-II trial. Ann Hematol 77: 225-229, 1998.

18. Quintas-Cardama A, Kantarjian H, Garcia-Manero G, et al: A pilot study of imatinib, low-dose cytarabine and idarubicin for patients with chronic myeloid leukemia in myeloid blast phase Leuk Lymphoma 48: 283-289, 2007.

19. Pytel D, Wysocki T and Majsterek I: Comparative study of DNA damage, cell cycle and apoptosis in human K562 and CCRF-CEM leukemia cells: role of BCR/ABL in therapeutic resistance. Comp Biochem Physiol C Toxicol Pharmacol 144 85-92, 2006.

20. Blasiak J, Gloc E, Wozniak K, et al: Genotoxicity of idarubicin and its modulation by vitamins $\mathrm{C}$ and $\mathrm{E}$ and amifostine. Chem Biol Interact 140: 1-18, 2002

21. Mosmann T: Rapid colorimetric assay for cellular growth and survival: application to proliferation and cytotoxicity assays. J Immunol Methods 65: 55-63, 1983.

22. Belloc F, Belaud-Rotureau MA, Lavignolle V, et al: Flow cytometry detection of caspase 3 activation in preapoptotic leukemic cells. Cytometry 40: 151-160, 2000

23. Vial JP, Belloc F, Dumain P, et al: Study of the apoptosis induced in vitro by antitumoral drugs on leukaemic cells. Leuk Res 21: 163-172, 1997.

24. Lotfi K, Zackrisson AL and Peterson C: Comparison of idarubicin and daunorubicin regarding intracellular uptake, induction of apoptosis, and resistance. Cancer Lett 178: 141-149, 2002.

25. Li F: Role of survivin and its splice variants in tumorigenesis. $\mathrm{Br}$ J Cancer 92: 212-216, 2005

26. Notarbartolo M, Cervello M, Dusonchet L, et al: Resistance to diverse apoptotic triggers in multidrug resistant HL60 cells and its possible relationship to the expression of P-glycoprotein Fas and of the novel anti-apoptosis factors IAP (inhibitory of apoptosis proteins). Cancer Lett 180: 91-101, 2002.

27. Vermeulen K, Van Bockstaele DR and Berneman ZN: Apoptosis: mechanisms and relevance in cancer. Ann Hematol 84: 627-639, 2005.

28. Chiou SK, Jones MK and Tarnawski AS: Survivin-an antiapoptosis protein: its biological roles and implications for cancer and beyond. Med Sci Monit 9: 25-29, 2003.
29. Beardmore VA, Ahonen LJ, Gorbsky GJ and Kallio MJ: Survivin dynamics increases at centromeres during G2/M phase transition and is regulated by microtubule-attachment and Aurora B kinase activity. J Cell Sci 117: 4033-4042, 2004.

30. Hanahan D and Weinberg RA: The hallmarks of cancer. Cell 100: 57-70, 2000.

31. Altieri DC: New wirings in the survivin networks. Oncogene 27: 6276-6284, 2008.

32. Mita AC, Mita MM, Nawrocki ST and Giles FJ: Survivin: key regulator of mitosis and apoptosis and novel target for cancer therapeutics. Clin Cancer Res 14: 5000-5005, 2008.

33. Carter BZ, Wang RY, Schober WD, et al: Targeting survivin expression induces cell proliferation defect and subsequent cell death involving mitochondrial pathway in myeloid leukemic cells. Cell Cycle 2: 488-493, 2003.

34. Gu CM, Zhu YK, Ma YH, et al: Knockdown of survivin gene by vector-based short hairpin RNA technique induces apoptosis and growth inhibition in Burkitt's lymphoma Raji cell line. Neoplasma 53: 206-212, 2006.

35. Jin HO, Yoon SI, Seo SK, et al: Synergistic induction of apoptosis by sulindac and arsenic trioxide in human lung cancer A549 cells via reactive oxygen species-dependent down-regulation of survivin. Biochem Pharmacol 72: 1228-1236, 2006.

36. Sato A, Ito K, Asano T, et al: Synergistic effect of survivinspecific small interfering RNA and topotecan in renal cancer cells: topotecan enhances liposome-mediated transfection by increasing cellular uptake. Int J Oncol 30: 695-700, 2007.

37. Zhen HN, Li LW, Zhang W, et al: Short hairpin RNA targeting survivin inhibits growth and angiogenesis of glioma U251 cells. Int J Oncol 31: 1111-1117, 2007.

38. Reiffers J, Huguet F, Stoppa AM, et al: A prospective randomized trial of idarubicin vs daunorubicin in combination chemotherapy for acute myelogenous leukemia of the age group 55 to 75 . Leukemia 10: 389-395, 1996.

39. Chandele A, Prasad V, Jagtap JC, et al: Upregulation of survivin in $\mathrm{G} 2 / \mathrm{M}$ cells and inhibition of caspase 9 activity enhances resistance in staurosporine-induced apoptosis. Neoplasia 6: 29-40, 2004.

40. Durrieu F, Belaud-Rotureau MA, Lacombe F, et al: Synthesis of Bcl-2 in response to anthracycline treatment may contribute to an apoptosis-resistant phenotype in leukemic cell lines. Cytometry 36: 140-191, 1999.

41. Kwee JK, Luque DG, Ferreira AC, et al: Modulation of reactive oxygen species by antioxidants in chronic myeloid leukemia cells enhances imatinib sensitivity through survivin downregulation. Anticancer Drugs 19: 975-981, 2008.

42. Maia RC, Vasconcelos FC, de Sá Bacelar T, et al: LQB-118, a pterocarpanquinone structurally related to lapachol [2-hydroxy3-(3-methyl-2-butenyl)-1,4-naphthoquinone]: a novel class of agent with high apoptotic effect in chronic myeloid leukemia cells. Invest New Drugs: May 25, 2010 (Epub ahead of print).

43. Altieri DC: Survivin, cancer networks and pathway-directed drug discovery. Nat Rev Cancer 8: 61-70, 2008.

44. Liu FT, Kelsey SM, Newland AC and Jia L: Generation of reactive oxygen species is not involved in idarubicin-induced apoptosis in human leukeamic cells. Br J Haematol 115: 817-825, 2001.

45. Carvalho A, Carmena M, Sambade C, et al: Survivin is required for stable checkpoint activation in taxol-treated HeLa cells. J Cell Sci 116: 2987-2998, 2003. 